\title{
Qualidade de vida no trabalho e risco de adoecimento: estudo no poder judiciário brasileiro ${ }^{1}$
}

\author{
Lívia Carolina Fernandes ${ }^{a^{*}}$ \\ Mário César Ferreirab \\ ${ }^{a}$ Eletrobras Eletronorte. Brasília, DF, Brasil \\ 'Universidade de Brasília, Instituto de Psicologia. Brasília, DF, Brasil
}

\begin{abstract}
Resumo: A pesquisa visou caracterizar a Qualidade de Vida no Trabalho (QVT) em um órgão do Poder Judiciário com base na percepção de seus trabalhadores. A abordagem teórico-metodológica adotada foi a Ergonomia da Atividade Aplicada à Qualidade de Vida no Trabalho (EAA_QVT). Participaram da pesquisa 5.164 trabalhadores. A análise quantitativa apontou que, globalmente, os trabalhadores avaliam a QVT em uma zona de bem-estar moderado. O fator mais crítico foi "organização do trabalho", enquanto o fator avaliado mais positivamente foi "elo trabalhovida social". A pesquisa forneceu subsídios para uma intervenção que consolide as fontes de bem-estar, visando à prevenção de agravos à saúde e à promoção da QVT.
\end{abstract}

Palavras-chave: qualidade de vida no trabalho, bem-estar, mal-estar, ergonomia da atividade, poder judiciário.

\section{Introdução}

O importante jurista brasileiro Rui Barbosa, em 1920, já afirmava que "Justiça atrasada não é justiça, senão injustiça qualificada e manifesta" (Barbosa, 1920). Quase um século após a manifestação do citado jurista, verifica-se que esse discurso nunca foi tão atual, pois a morosidade e as deficiências na aplicação da Justiça estão, não raramente, na pauta dos noticiários (Empresa Brasil de Comunicação [EBC], 2013; Gama \& Roncaglia, 2013; Morosidade, 2012; Sadek \& Arantes, 1994; Souza, 2013; Yoshimine, 2012). Nesse contexto, os cidadãos-usuários demonstram insatisfação com a lentidão dos processos judiciais, como ilustram os relatórios da Ouvidoria do CNJ, segundo os quais a morosidade processual no Poder Judiciário tem ocupado recorrentemente o topo do ranking das reclamações (Conselho Nacional de Justiça, n.d.; 2012).

Em função do descontentamento da sociedade brasileira, a pressão social sobre os órgãos e sobre os trabalhadores do Judiciário tem sido intensa. Entretanto, sabe-se que a resistência dos trabalhadores é finita, e a pressão e a sobrecarga excessivas não estão relacionadas ao aumento da produtividade (Campos, 2008; Putkonen, 2009). Além de não favorecer o aumento da produtividade, o excesso de pressão e sobrecarga pode contribuir para o adoecimento

1 Trabalho produzido com apoio de bolsa de produtividade do CNPq. Artigo derivado da dissertação "Estamos o tempo todo enxugando gelo": Qualidade de Vida no Trabalho e Vivências de Bem-Estar e Mal-Estar em um Órgão do Poder Judiciário, defendida em 26.03.2013 e aprovada no PPG Psicologia Social, do Trabalho e das Organizações (PSTO) do Instituto de Psicologia da Universidade de Brasília (UnB), de autoria de Lívia Carolina Fernandes, orientada pelo Prof. Dr. Mário César Ferreira.

* Autor correspondente: liviacarolina@msn.com do trabalhador, comprometendo o desempenho e o alcance da missão organizacional (Carvalho \& Moraes, 2011). Contrariamente, o incremento da produtividade é favorecido nos contextos de trabalho em que a Qualidade de Vida no Trabalho (QVT) é presente (Lima, Santos Jr., \& Xavier, 2011).

Visando solucionar a lentidão dos processos judiciais, aumentar a eficácia de suas decisões e diminuir a disparidade existente entre a estrutura do Judiciário e os avanços sociais, o processo de modernização do Poder Judiciário, impulsionado em 2004, envolveu inovações tecnológicas, determinação de metas e mudanças na organização do trabalho, impondo novas exigências aos trabalhadores. Tais exigências podem ser ilustradas por estudos que apontam que os trabalhadores do Poder Judiciário são submetidos a pressão social, falta de reconhecimento, intensificação do ritmo de trabalho, volume cumulativo e sobrecarga de trabalho, alto nível de exigência de produtividade, falta de autonomia e priorização da quantidade de julgados em detrimento da qualidade, comprometendo a organização do trabalho e potencializando vivências de mal-estar no trabalho (Andrade, 2011; Brasil, 2009; Fernandes \& Vasques-Menezes, 2012; Jorge, 2009; Moura, 2009; Prudêncio, Faria \& Andrade, 2003; Tavares, 2003; Sadek, 2004; Sadek \& Arantes, 1994; Silva, 2004). Esse cenário torna-se ainda mais complexo em função das condições de trabalho no serviço público brasileiro, consideradas insatisfatórias apesar das melhorias conquistadas nos últimos anos (Bellusci \& Fischer, 1999; Brasil, 2003; Gomes, Silva, \& Sória, 2012).

A presente pesquisa foi realizada em um dos cinco Tribunais Regionais Federais, instalados no dia 30 de março de 1989, tendo Brasília, Rio de Janeiro, São Paulo, Porto Alegre e Recife como sedes, respectivamente, das 1, 
$2^{\mathrm{a}}, 3^{\mathrm{a}}, 4^{\mathrm{a}}$ e $5^{\mathrm{a}}$ Regiões (Moraes, 2006). O Tribunal julgou, em 2011, 532.871 processos, o que corresponde a $12,3 \%$ a mais do que no ano anterior. Apesar do aumento do número de julgamentos, o acúmulo de ações ainda é grande. Em função do descompasso entre a quantidade de ações que dão entrada e o número de processos julgados, o órgão tem buscado tornar seu processo mais eficiente, adotando iniciativas como a automação da informação e a otimização dos processos de trabalho.

Diante desse cenário de intensificação do trabalho e de pressão social, a QVT no contexto do Poder Judiciário é uma questão preocupante que deve ser investigada na perspectiva de compreender o trabalho para transformá-lo (Guérin, Laville, Daniellou, Duraffoug, \& Kerguelen, 2001). Assim, o objetivo geral desta pesquisa consistiu em caracterizar a QVT de um órgão do Poder Judiciário com base na percepção de seus trabalhadores. A questão que orientou o processo de investigação foi a seguinte: "Em que medida a percepção dos fatores estruturantes de QVT dos trabalhadores pode mostrar indícios de risco de adoecimento?".

\section{Quadro Teórico de Referência}

A introdução de inovações tecnológicas e organizacionais não é um "privilégio" do Poder Judiciário. Há cerca de meio século, a reestruturação produtiva tem impulsionado transformações profundas e aceleradas no mundo do trabalho. Todavia, tal processo tem sido acompanhado da produção de indicadores críticos como erros, retrabalho, queda da produtividade e da qualidade, aumento do absenteísmo, do presenteísmo, de acidentes e doenças do trabalho, de suicídios e de queixas e reclamações dos clientes e cidadãos-usuários (Ferreira, 2012). Destaca-se que esses indicadores podem ser intensificados pelo incentivo à competitividade exacerbada e pelo consequente enfraquecimento das redes de cooperação, situações muito presentes no contexto da reestruturação produtiva (Bruch \& Monteiro, 2011; Franco, Druck, \& Seligmann-Silva, 2010).

Os riscos de adoecimento dos trabalhadores vêm se agravando em face deste cenário de aceleração das atividades de trabalho - produzido, sobretudo, pelo forte uso das Novas Tecnologias da Informação e da Comunicação (NTIC) - e pela intensificação do processo de trabalho. Nesse contexto, verifica-se o aumento da incidência dos casos de burnout (Bragard, Dupuis, Razavi, Reynaert, \& Etienne, 2012; Norlund, Reuterwall, Höög, Lindahl, Janlert, \& Birgander, 2010; Rice, Rady, Hamrick, Verheijde, \& Pendergast, 2008); de distresse (Bawden \& Robinson, 2008; Blanch \& Stecher, 2009), e de Distúrbios Osteomusculares Relacionados ao Trabalho (Caetano, Cruz, Silva, Leite, \& Carvalho, 2012; Waters, Dick, \& Krieg, 2011). Tais indicadores críticos têm colocado a questão da QVT na agenda de trabalho das organizações privadas e públicas (Ferreira, 2008). Assim, os efeitos da reestruturação produtiva sobre os trabalhadores têm levado gestores e pesquisadores a se preocuparem com a QVT.
Entretanto, embora o crescente interesse por QVT pareça animador, uma análise mais aprofundada mostra que nem sempre o aparente cuidado das organizações com os trabalhadores é genuíno. Segundo Padilha (2010), a QVT tem se configurado como um "meio" para se alcançar ganhos de produtividade quando deveria ser um "fim". Nessa concepção, os problemas e suas causas são negados, e as práticas de QVT são adotadas como "válvulas de escape" para proporcionar alívio e sensação imediata de bem-estar. Desse modo, o interesse das organizações pela melhoria da QVT tem sido motivado muito mais pela produtividade do que pelo bem-estar dos trabalhadores. Esse ponto de vista é compartilhado por Ferreira (2011), que considera que as práticas de QVT de cunho assistencialista buscam demonstrar ao trabalhador o quanto a organização preocupa-se com seu 'bem-estar' visando obter, como contrapartida, envolvimento mais intenso com o trabalho. Assim, tais práticas de QVT remetem às velhas estratégias de sedução gerencial para garantir o comprometimento no trabalho e os desempenhos esperados.

\section{A Abordagem "Ergonomia da Atividade Aplicada à Qualidade de Vida no Trabalho (EAA_QVT)"}

Contrapondo a concepção assistencialista de QVT, Ferreira (2006) propôs uma atuação com base em viés preventivo e de promoção da saúde. A abordagem contra-hegemônica considera que a intervenção eficaz e duradoura no campo da QVT implica em inverter o paradigma dominante do "trabalhador como variável de ajuste" para o preconizado pela Ergonomia, de "adaptar o trabalho ao ser humano" (Ferreira, 2011).

Desse modo, Ferreira (2012) propôs a abordagem teórico-metodológica da Ergonomia da Atividade Aplicada à Qualidade de Vida no Trabalho (EAA_QVT), empregada para a análise dos dados empíricos da presente pesquisa. Nesta perspectiva, as bases conceituais, que são aderentes ao objetivo do presente artigo, englobam uma breve caracterização da Ergonomia da Atividade (disciplina de referência da pesquisa) e a definição de Qualidade de Vida no Trabalho.

O conceito de Ergonomia adotado nesta pesquisa é o proposto por Ferreira:

abordagem científica antropocêntrica que se fundamenta em conhecimentos interdisciplinares das ciências humanas e da saúde para, de um lado, compatibilizar os produtos e as tecnologias com as características e necessidades dos usuários e, de outro, humanizar o contexto sociotécnico de trabalho, adaptando-o tanto aos objetivos do sujeito e/ou grupo, quanto às exigências das tarefas e das situações de trabalho. (Ferreira, 2012, p. 139)

Quanto ao conceito de QVT, Ferreira o define da seguinte forma: 
Sob a ótica das organizações, a QVT é um preceito de gestão organizacional que se expressa por um conjunto de normas, diretrizes e práticas no âmbito das condições, da organização e das relações socioprofissionais de trabalho que visa à promoção do bem-estar individual e coletivo, o desenvolvimento pessoal dos trabalhadores e o exercício da cidadania organizacional nos ambientes de trabalho. Sob a ótica dos trabalhadores, ela se expressa por meio das representações globais (contexto organizacional) e específicas (situações de trabalho) que estes constroem, indicando o predomínio de experiências de bem-estar no trabalho, de reconhecimentos institucional e coletivo, de possibilidade de crescimento profissional e de respeito às características individuais. (Ferreira, 2012, p. 172)

O modelo teórico-descritivo da EAA_QVT tem como foco articular a pesquisa e a intervenção nas organizações, apresentando dois níveis analíticos distintos e complementares - macroergonômico e microergonômico (Figura 1).

No nível macroergonômico, identifica-se a QVT com base em um continuum de representações dos trabalhadores que estão polarizadas em duas modalidades de representações afetivas: bem-estar e mal-estar no trabalho. A vivência duraroura de bem-estar no trabalho delineia um cenário de QVT, enquanto o predomínio de vivências de mal-estar no trabalho significa ausência de QVT e risco de adoecimento. Cabe destacar que as representações de bemestar e de mal-estar no trabalho possuem uma dinâmica pendular, que oscila no eixo risco de adoecimento-saúde. Entre os polos do continuum, o modelo apresenta ainda uma zona intermediária de coabitação de sentimentos negativos e positivos, demonstrando que não há uma fronteira clara de onde começam e de onde terminam os sentimentos de bem-estar e de mal-estar no trabalho (Ferreira, 2011).

As representações de bem-estar e de mal-estar no trabalho têm origem em cinco fatores, a saber: Condições de Trabalho, Organização do Trabalho, Relações Socioprofissionais de Trabalho, Reconhecimento e Crescimento Profissional, e Elo Trabalho-Vida Social. A cultura organizacional, que constitui o "cenário" em que se inscrevem os fatores e tem importância estratégica para interpretar a QVT, finaliza a descrição do nível macroergonômico (Ferreira, 2011), o qual é avaliado com base na aplicação do Inventário de Avaliação de Qualidade de Vida no Trabalho (IA_QVT) (Ferreira, 2009).

Enquanto o nível macroergonômico avalia as representações dos trabalhadores relacionadas aos fatores estruturantes de QVT, o nível microergonômico investiga os impactos desses fatores e o modo pelo qual os trabalhadores lidam com as exigências do contexto de trabalho. $\mathrm{Na}$ análise microergonômica, a compreensão da QVT baseiase em duas dimensões: custo humano do trabalho (CHT) e estratégias de mediação individual e coletiva (EMIC) (Ferreira, 2011).

Entre as pesquisas que adotadaram a EAA_QVT como abordagem teórico-metodológoca, detacam-se Andrade (2011), Branquinho (2010), Daniel (2012), Feitosa (2010) e Pacheco (2011). O presente trabalho adota parcialmente o modelo da EAA_QVT, tendo em vista que se limita ao diagnóstico macroergonômico.

\section{Abordagem Metodológica}

As características metodológicas da pesquisa são apresentadas a seguir.

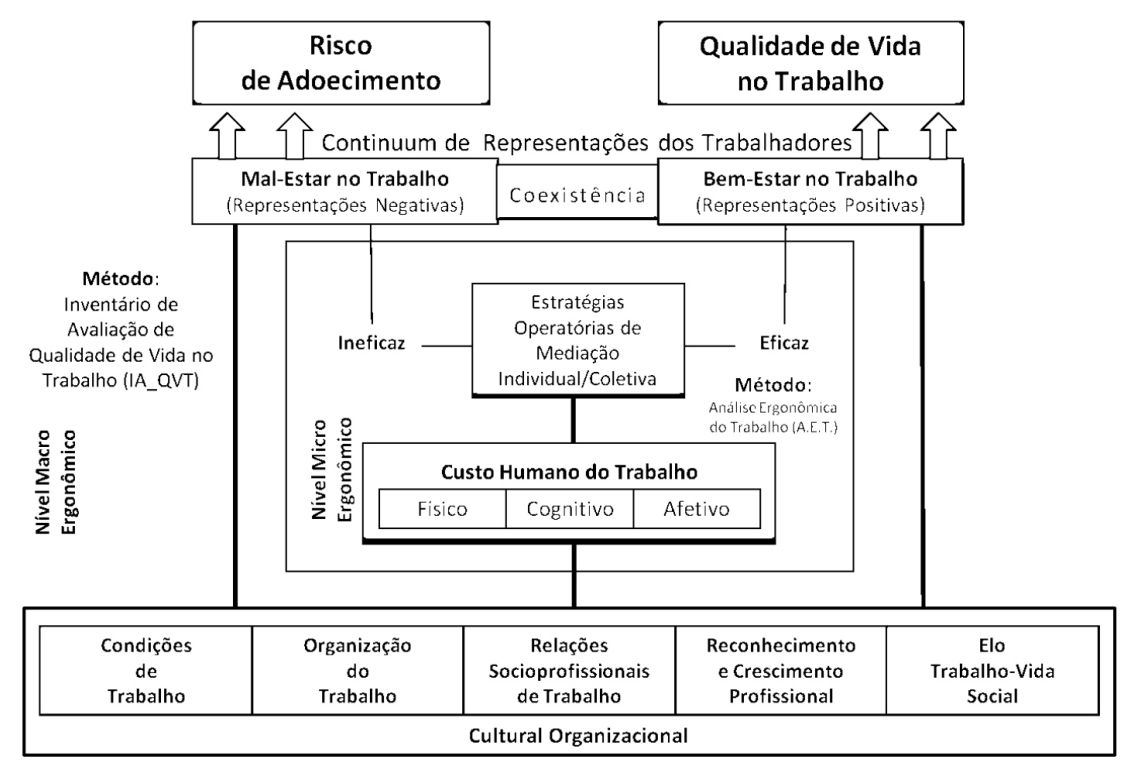

Figura 1. Modelo Teórico-Metodológico de Avaliação de Qualidade de Vida no Trabalho (QVT): Níveis Analíticos, Fatores Estruturadores e Métodos.

Fonte: Ferreira (2012) 


\section{Participantes}

$\mathrm{O}$ instrumento de coleta de dados foi disponibilizado a todos os trabalhadores do órgão. No período em que os dados foram coletados, havia 13.129 trabalhadores na instituição. Participaram da pesquisa 5.164 pessoas, o que corresponde a 39,34\% do coletivo de trabalhadores. A taxa de participação pode ser considerada expressiva e reflete o sucesso do cuidadoso trabalho de sensibilização.

Os perfis demográfico e profissional dos participantes apresentaram as seguintes características: $54 \%$ do sexo masculino; $32,55 \%$ com especialização; $40,59 \%$ são divorciados; $71 \%$ são servidores; $65 \%$ ocupam função comissionada; $33 \%$ possuem faixa etária entre 36 e 46 anos; tempo médio de trabalho no órgão de 7,9 anos $(\mathrm{DP}=9,3)$.

\section{Instrumento de Pesquisa}

Para a coleta de dados, utilizou-se a parte quantitativa do Inventário de Avaliação de Qualidade de Vida no Trabalho (IA QVT), validado por Ferreira (2009). O questionário contemplou campos para assinalar as variáveis demográficas e profissiográficas e era acessado pelo respondente após a leitura de uma tela inicial de instruções. Tais instruções explicitavam as seguintes informações: objetivo da pesquisa; importância da participação e responsabilidade acadêmica. Além dessas informações, a tela inicial informava, com base nas orientações da Resolução MS 196/96, do Conselho Nacional de Saúde, diretrizes éticas relativas: (a) à participação voluntária; (b) à possibilidade de desistência em participar a qualquer tempo sem acarretar nenhum prejuízo ou dano pessoal; (c) à inexistência de riscos para as atividades de trabalho ou para o órgão; (d) ao sigilo ético no tratamento dos resultados; e (e) à liberdade para não se identificar. Ao término do preenchimento do questionário, o respondente deveria acionar comando para salvar os dados.

\section{Procedimentos}

Inicialmente, realizou-se uma análise de documentos institucionais, visando conhecer melhor o contexto de trabalho do órgão pesquisado. Para a coleta de dados, optou-se por utilizar a versão digital do IA_QVT por ser menos onerosa e oferecer ganho de tempo. Após a preparação e adaptação do instrumento, fez-se o pré-teste de interface, que permitiu revisar a forma e o conteúdo e implementar as alterações necessárias. Posteriormente, foi realizada a sensibilização, que contou com o apoio da área de comunicação do órgão. Por fim, após o tratamento dos dados e elaboração de um relatório, foi realizada a devolutiva dos resultados aos trabalhadores.

\section{Tratamento dos Resultados}

O tratamento dos dados foi feito com o aplicativo Pacote Estatístico para as Ciências Sociais (SPSS). Para a interpretação dos achados, utilizou-se uma cartografia

Exemplo de Item

As oportunidades de crescimento profissional são iguais para todos

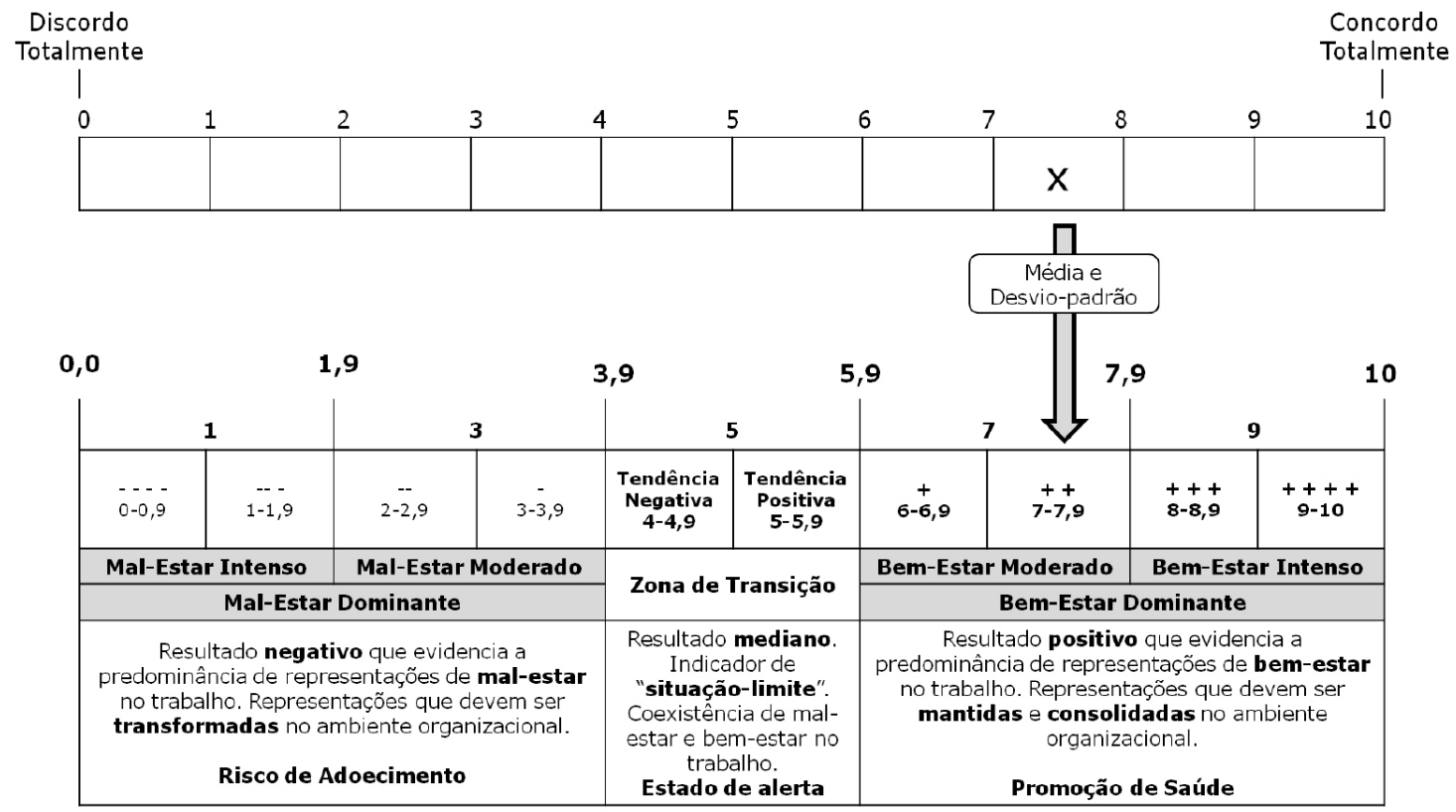

Figura 2. Cartografia Psicométrica

Fonte: Ferreira (2012). 
psicométrica segundo a qual o resultado do diagnóstico pode se enquadrar em três zonas distintas: (1) risco de adoecimento, (2) estado de alerta e (3) promoção da saúde (Figura 2).

A primeira zona é a de Mal-Estar Dominante e representa o polo negativo, pois evidencia a predominância de representações de mal-estar no trabalho que devem ser transformadas. Esta zona compreende o intervalo entre 0 e 3,9; e é subdividida em Mal-Estar Intenso e Mal-Estar Moderado. A segunda zona é a de transição, interpretada como resultado mediano que indica "situação-limite". Esta zona representa a coexistência de mal-estar e bem-estar no trabalho e contempla o intervalo entre 4 e 5,9, sendo subdividida em Tendência Negativa e Tendência Positiva. Por fim, a terceira zona é a de Bem-Estar Dominante e caracteriza o polo positivo da cartografia, evidenciando a predominância de representações de bem-estar no trabalho que devem ser mantidas e consolidadas no ambiente organizacional. Esta zona situa-se no intervalo entre 6 e 10, e é subdividida em Bem-Estar Moderado e Bem-Estar Intenso (Ferreira, 2012).

\section{Resultados e Discussão}

Neste tópico, os resultados encontrados na pesquisa são apresentados e discutidos à luz do quadro teórico de referência.

\section{Nota Global de QVT}

A percepção global de QVT dos trabalhadores resultou em uma média de 6,28, com desvio-padrão de 1,41, indicando que o órgão encontra-se na zona de Bem-Estar Moderado. Destaca-se que esse é um resultado positivo que indica promoção da saúde e evidencia o predomínio de representações de bem-estar no trabalho, as quais devem ser mantidas e consolidadas.

O resultado global de QVT, no âmbito da instituição, foi bastante satisfatório, se comparado com outros diagnósticos realizados pelo ErgoPublic/Universidade de Brasília (Andrade, 2011; Branquinho, 2010; Feitosa, 2010; Pacheco, 2011), conforme pode ser observado na Figura 3.

Assim, considera-se importante identificar os fatores que promovem o bem-estar no trabalho no órgão, para que sejam preservados e reforçados, e os fatores desencadeadores de mal-estar no trabalho, para que sejam transformados visando à promoção da QVT. A seguir, serão detalhados os cinco fatores estruturantes de QVT.

\section{Fator Condições de Trabalho}

As Condições de Trabalho foram avaliadas com média de 6,95, indicando que há predominância de bem - estar no trabalho. A maior queixa dos trabalhadores refere-se à inadequação do mobiliário (média de 6,16), enquanto o item mais bem avaliado foi o relacionado à suficiência da iluminação (média de 8,14). Embora o fator Condições de Trabalho esteja localizado na zona de BemEstar Dominante, constatou-se que o item relacionado ao mobiliário situa-se na área limítrofe à zona de transição, indicando que em algumas áreas do órgão há a necessidade de realizar adequações.

Por um lado, o resultado desse fator é similar aos encontrados por Andrade (2011), Branquinho (2010) e Pacheco (2011), que constataram que as condições de trabalho em outros órgãos públicos também se situam na zona de Bem-Estar Dominante. Por outro lado, estudos apontam que em outras organizações as condições de trabalho são

$\square$ Presente Estudo $\square$ Branquinho, $2010 \square$ Andrade, $2011 \square$ Pacheco, $2011 \square$ Feitosa, 2010

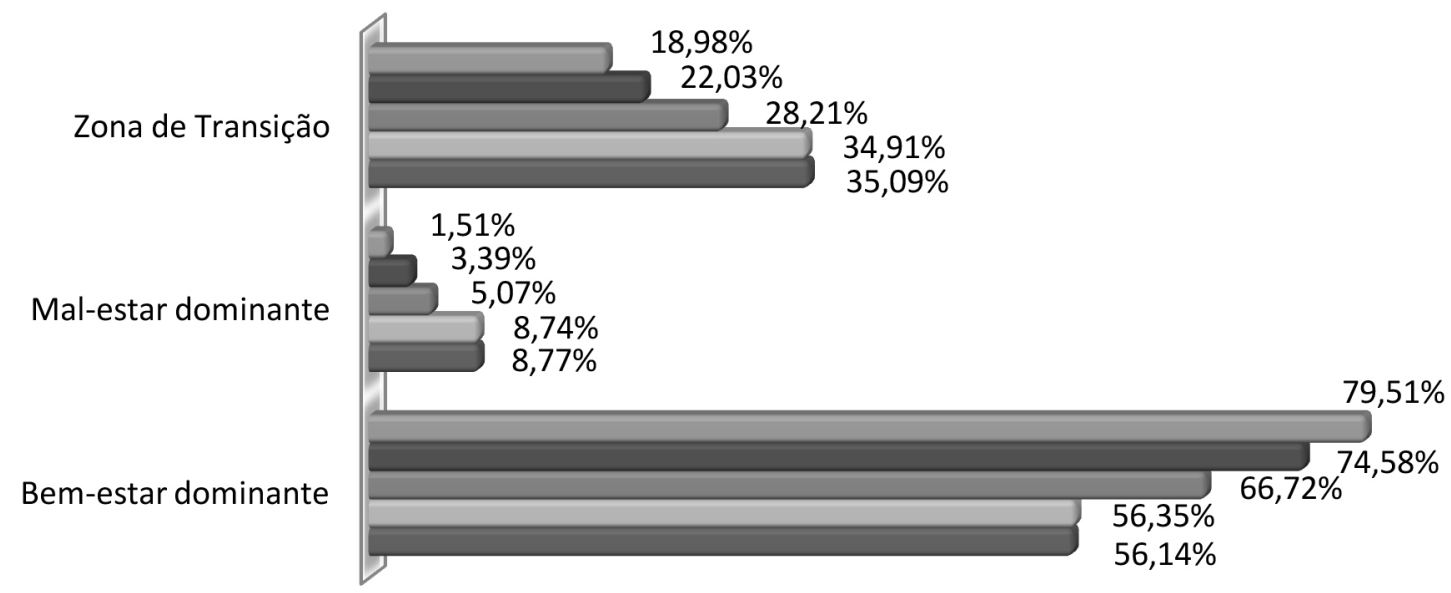

Figura 3. Comparação com outros diagnósticos que adotaram o IA_QVT.

Fonte: autoria própria. 
inadequadas e oferecem risco de adoecimento aos trabalhadores (Bellusci \& Fischer, 1999; Feitosa, 2010).

As condições de trabalho no funcionalismo público ficaram mais precárias na década de 1990, quando o governo brasileiro aderiu ao "Consenso de Washington" e passou a tratar o emprego público como um problema fiscal, atuando no sentido de restringir sua dimensão e seus custos. Na década seguinte, o documento Gestão pública para um Brasil de todos (Brasil, 2003) trouxe diretrizes no sentido de reestruturar o serviço público e melhorar as condições e as relações de trabalho, visando atender às demandas sociais e tornar o Estado mais eficiente, inclusivo e equitativo. Embora tenha havido manutenção de parte da postura conservadora dos anos 1990, Gomes, Silva e Sória (2012) consideram que houve melhorias nas condições de trabalho do servidor público. Contudo, tais melhorias não ocorreram de forma homogênea.

Desse modo, a adequação das condições de trabalho em alguns órgãos públicos pode ser decorrente dessa política de recursos humanos estabelecida na década de 2000. Entretanto, como salientam Gomes, Silva e Sória (2012), a implantação dessa política foi marcada por ambiguidades, o que pode explicar o fato de que a melhoria nas condições de trabalho não contemplou todos os órgãos na dimensão desejada.

Diante dos resultados apontados pelo presente estudo, cabe ao órgão manter e aprimorar as condições de trabalho tendo em vista que elas constituem um ponto positivo, sempre atentando para as especificidades de cada setor.

\section{Fator Organização do Trabalho}

O fator Organização do Trabalho, constituído por nove itens, foi o que apresentou menor média $(3,59)$, localizada na zona de Mal-Estar Dominante. Na visão dos trabalhadores, a cobrança de prazos para realização das tarefas é o item mais negativo, enquanto a pressão na realização das tarefas constitui o aspecto que menos prejudica o bem-estar no trabalho, embora esteja situado na zona de transição. Esse resultado converge com achados de outras pesquisas que utilizaram o IA_QVT (Andrade, 2011; Branquinho, 2010; Feitosa, 2010; Pacheco, 2011), nas quais a organização do trabalho foi o fator que apresentou a menor média.

O contexto de trabalho do Poder Judiciário também foi objeto de estudo de Tavares (2003), que constatou que problemas na organização do trabalho, como volume cumulativo de trabalho e a falta de autonomia, constituem fonte de sofrimento no trabalho para os servidores. Segundo Fernandes e Vasques-Menezes (2012), diversos estudos baseados em diferentes abordagens, como a psicodinâmica do trabalho, a ergonomia e o estresse ocupacional, têm identificado, de forma consensual, relações entre a organização do trabalho e o mal-estar no trabalho.

O cenário de cobrança excessiva que marca o Poder Judiciário pode resultar das transformações que vêm ocorrendo nos serviços públicos, caracterizadas pelo fortalecimento dos regimes democráticos e pela postura mais vigilante e reivindicatória dos cidadãos-usuários quanto à qualidade dos serviços públicos prestados (Ferreira, 2008). Sadek (2004) observa que, nos últimos tempos, tornou-se dominante a ideia de que as instituições do Poder Judiciário são incapazes de responder à crescente demanda por Justiça e que elas estão obsoletas e resistentes a qualquer modificação. Assim, o Poder Judiciário passou a ser percebido como problemático, de modo que o grau de tolerância com a baixa eficiência e o seu prestígio têm sido cada vez menores. Diante desse cenário, a pressão pela modernização e pela eficiência dos serviços prestados tem aumentado, impactando no dia-a-dia dos servidores, que são cobrados para atingir as metas estabelecidas pelo Conselho Nacional de Justiça (CNJ). Aliado a isso, os servidores ainda enfrentam um quadro de mudanças e novas exigências relacionadas à organização do trabalho decorrentes da modernização do Poder Judiciário.

Silva (2004) considera que o aumento das demandas judiciais, a sobrecarga de trabalho e a pressão social pelo aumento da produtividade têm imposto uma intensificação do ritmo de trabalho e um desempenho que, muitas vezes, extrapola os limites físicos e mentais dos trabalhadores, deteriorando a QVT e comprometendo a eficiência do Judiciário. Este autor ressalta ainda a necessidade de encontrar um ponto de equilíbrio entre a QVT e a eficiência, e defende que é preciso investir em ações preventivas.

De acordo com o exposto, fica evidente que a organização do trabalho no órgão pesquisado é um indicador crítico, que deve ser tratado com urgência. Aliar $o$ atendimento a uma demanda de trabalho que cresce a cada dia com uma estrutura que não aumenta na mesma proporção, sem criar um contexto de trabalho adoecedor, é o grande desafio.

\section{Fator Relações Socioprofissionais de Trabalho}

De modo geral, as Relações Socioprofissionais de Trabalho foram enquadradas na zona de Bem-Estar Moderado, com média de 7,22. A harmonia nas relações com os colegas de trabalho foi o item mais positivamente avaliado, enquanto a falta de liberdade para dizer o que pensa sobre o trabalho constitui o aspecto mais crítico.

Esse resultado encontra eco nos estudos realizados por Andrade (2011), Branquinho (2010), Feitosa (2010) e Pacheco (2011) com o uso do IA_QVT, nos quais as relações socioprofissionais apareceram como fonte de bem-estar no trabalho.

Bruch e Monteiro (2011), com base no referencial da Psicodinâmica do Trabalho, afirmam que as relações socioprofissionais podem contribuir significativamente para a resistência - entendida como modo de libertação do trabalhador da dominação e estabelecimento da solidariedade - e para a promoção e manutenção da saúde mental. As relações positivas, marcadas por amizade, cooperação, respeito e confiança mútua, contribuem para a elevação de sentimentos de satisfação e bem-estar no trabalho, 
transformando situações que levariam ao sofrimento em vivências prazerosas.

Segundo Ferreira (2012), as interações socioprofissionais promovem QVT quando são profícuas e benfazejas e, portanto, produtoras de bem-estar no trabalho. As relações socioprofissionais desempenham função compensadora no contexto laboral, principalmente, quando as condições e a organização do trabalho são críticas e precárias. Nessas situações, as redes de cooperação e os pactos viabilizam os objetivos das tarefas e os desempenhos esperados e evitam os impactos negativos para a saúde dos trabalhadores.

Desse modo, o órgão pesquisado deve envidar esforços para que as relações socioprofissionais continuem a ser fonte de bem-estar no trabalho, conservando e consolidando essas representações positivas no ambiente organizacional.

\section{Reconhecimento e Crescimento Profissional}

Embora o fator Reconhecimento e Crescimento Profissional esteja situado, de forma global, na zona de Bem-Estar Dominante, a média de 6,01 indica que esse resultado é limítrofe com a zona de transição. $\mathrm{O}$ item avaliado mais positivamente foi "A prática do reconhecimento contribui para a minha realização pessoal", enquanto o item que recebeu a pior avaliação foi "As oportunidades de crescimento profissional são iguais para todos".

Esse panorama é compatível com os resultados de Branquinho (2010) e Feitosa (2010), que verificaram que o fator Reconhecimento e Crescimento Profissional foi avaliado na zona de Bem-Estar Dominante, em estudos que adotaram o IA_QVT. Entretanto, Andrade (2011) e Pacheco (2011) chegaram a resultados diferentes, pois em seus estudos esse fator enquadrou-se na zona de transição, demonstrando que a prática do reconhecimento não é unanimidade no serviço público brasileiro.

No que se refere às oportunidades de crescimento na carreira no Poder Judiciário, Prudêncio, Faria e Andrade (2003) destacam que não há critérios objetivos para as promoções, de modo que os magistrados ficam submetidos a interesses distintos da prestação jurisdicional. Segundo esses autores, os magistrados sentem-se insatisfeitos com a falta de critérios para promoção, e consideram que essa prática é antidemocrática, premia os submissos ao invés dos merecedores, cria tensão interna e trata a função pública como particular, priorizando a amizade e o apadrinhamento.

Desse modo, embora o fator Reconhecimento e Crescimento Profissional esteja na zona de bem-estar dominante, o fato de quase metade dos itens estarem situados na zona de transição aponta a necessidade de reflexão e melhorias nos mecanismos relacionados a oportunidades de crescimento e reconhecimento.

\section{Fator Elo trabalho-Vida Social}

De modo geral, o fator Elo Trabalho-Vida Social enquadrou-se na zona de Bem-Estar Moderado (média de
7,61), e todos os itens, com exceção de um, situam-se na zona de Bem-Estar Dominante. O item mais bem avaliado foi o invertido "Sinto-me mais feliz no trabalho no [órgão] que com a minha família", enquanto a pior avaliação ficou por conta do item "A sociedade reconhece a importância do meu trabalho".

Esse resultado converge com os achados de Andrade (2011), Branquinho (2010), Feitosa (2010) e Pacheco (2011). Nos estudos realizados por essas autoras com o IA_QVT, o fator Elo Trabalho-Vida Social se situou na zona de BemEstar Dominante.

Segundo Padilha (2010), um dos principais fatores relacionados à QVT é a conciliação entre trabalho e vida pessoal, de modo que o tempo, os compromissos e as tensões do trabalho não afetem a esfera particular. A autora considera que o equilíbrio entre trabalho e vida pessoal não é vivenciado por grande parte dos trabalhadores que, imersos em um cenário de precarização, sofrem com os efeitos da intensificação e da flexibilização do trabalho.

Silva (2004) relata que a identidade profissional e pessoal dos trabalhadores tem sido abalada pela desvalorização social resultante de preconceitos e do descrédito do Judiciário, considerado lento, distante e ineficaz. Para reverter essa imagem negativa, o autor sugere que seja feita uma comunicação eficaz com a sociedade para divulgar a importância do trabalho realizado e as ações voltadas para tornar a prestação jurisdicional mais eficiente.

No órgão pesquisado, o elo trabalho-vida social é fonte de bem-estar no trabalho, sendo necessário manter e consolidar essas representações. Entretanto, o item que avalia o reconhecimento do trabalho pela sociedade apresentou média limítrofe entre as zonas de bem-estar moderado e de transição. Segundo Sadek e Arantes (1994), pesquisas de opinião têm demonstrado que grande parte da população manifesta descontentamento com o Judiciário. Assim, há a necessidade de investir na comunicação do importante trabalho realizado nessa instituição.

Desse modo, os resultados apontam que os trabalhadores, de modo global, têm representações positivas de QVT no órgão pesquisado. Ao desmembrar o resultado por fator avaliado, verifica-se que as Condições de Trabalho, as Relações Socioprofissionais de Trabalho, o Reconhecimento e Crescimento Profissional, e o Elo Trabalho-Vida Social apresentaram médias localizadas na zona de bem-estar dominante, enquanto a Organização do Trabalho localiza-se na zona de mal-estar dominante. No tópico a seguir, são apresentadas as conclusões da pesquisa, além das contribuições, dos limites e da proposta de agenda de pesquisa.

\section{Conclusão}

Há quem diga que o tempo é medida de Justiça. E, justamente, o tempo, ou melhor, a demora na finalização dos processos judiciais tem sido um dos motivos das diversas críticas direcionadas ao Poder Judiciário, considerado lento demais, além de inacessível aos excluídos, burocratizado, 
ineficiente e imprevisível. Paralelamente, tem sido registrado um vertiginoso crescimento nas demandas judiciais nos últimos tempos, sobrecarregando os trabalhadores incumbidos da tarefa de prestar jurisdição (Silva, 2004). Diante desse cenário, iniciou-se um movimento de modernização do Judiciário, na tentativa de tornar a Justiça célere, eficiente, e acessível aos cidadãos. Entretanto, os impactos destas transformações sobre a QVT dos trabalhadores do Poder Judiciário ainda não são amplamente conhecidos.

Retomando o objetivo geral desta pesquisa - caracterizar a QVT de um órgão do Poder Judiciário com base na percepção de seus trabalhadores - e diante dos resultados encontrados, pode-se afirmar que, de modo global, os trabalhadores percebem positivamente a QVT no órgão. Entretanto, a média geral está bastante próxima, conforme a cartografia psicométrica, da zona de transição, apontando a necessidade de atuar nos fatores estruturantes de QVT percebidos de modo mais negativo pelos trabalhadores.

O fator mais crítico, na visão dos trabalhadores, foi a Organização do Trabalho, localizado na zona de mal-estar dominante. Os resultados do presente estudo indicam que a organização do trabalho tem sido fonte de mal-estar para os trabalhadores, sendo necessário atuar no sentido de implantar melhorias e retirar os trabalhadores da exposição ao risco de adoecimento. Segundo Ferreira (2012), mudanças na organização do trabalho, como a introdução e uso de novas tecnologias, a prescrição de novos procedimentos de trabalho, a gestão do ritmo de trabalho e a reorganização dos horários de trabalho devem ser sempre precedidas de um planejamento participativo, com o envolvimento dos trabalhadores.

O fator avaliado de forma mais positiva foi Elo Trabalho-Vida Social. Segundo Ferreira (2012), a importância que os trabalhadores atribuem ao elo trabalho-vida social contraria os valores dos modelos de gestão organizacional e do trabalho que insistem na clivagem entre o mundo do trabalho (organizações) e o mundo da vida privada (família, casa, amigos), de modo velado ou explícito. Desse modo, é necessário ter uma visão holística do trabalho, considerando que o tempo vivido na organização é um prolongamento daquilo que é vivido em outras esferas da vida. Diante do resultado, faz-se necessário que o órgão mantenha e consolide essas representações positivas relacionadas ao elo entre trabalho e vida social, e promova a saúde no ambiente organizacional.

Com relação à questão norteadora da pesquisa "Em que medida a percepção dos fatores estruturantes de QVT dos trabalhadores pode mostrar indícios de risco de adoecimento?" -, verifica-se que a organização do trabalho, fator estruturante de QVT situado na zona de Mal-Estar Moderado, constitui um risco de adoecimento no órgão investigado. Desse modo, é necessário investir em uma organização saudável do trabalho que minimize a sobrecarga, a cobrança e a pressão na realização das atividades de trabalho, e favoreça a promoção da QVT. Neste sentido, o enfrentamento consequente de tais indicadores críticos que colocam em risco a saúde requer conceber e implantar um processo de humanização do modelo de gestão do trabalho. Tal processo implica, entre outras medidas, em proporcionar a efetiva participação dos servidores no processo de tomada de decisões e, sobretudo, o redesenho dos processos de trabalho e de tarefas, incorporando a experiência, as necessidades e as expectativas dos trabalhadores. Os achados fornecem indícios para a realização de uma intervenção que gere impactos positivos sobre a prestação jurisdicional, tendo em vista que a QVT está relacionada com o aumento da produtividade que, no caso do Poder Judiciário, significa mais processos julgados com eficácia em menos tempo, atendendo aos anseios dos cidadãos.

No que se refere às contribuições da pesquisa, do ponto de vista acadêmico, destaca-se a pertinência teórica e metodológica da Ergonomia da Atividade Aplicada à Qualidade de Vida no Trabalho (EAA_QVT) que, longe de ser uma "panaceia" que resolva todos os problemas vivenciados pelos trabalhadores, mostrou-se uma alternativa eficaz para subsidiar transformações humanizadoras do contexto de trabalho investigado (Ferreira, 2008). Destacase, ainda, que a utilização da versão digital do instrumento de coleta de dados possibilitou a aplicação em todo o órgão e o rápido tratamento dos dados.

Do ponto de vista institucional, o diagnóstico ofereceu subsídios para o enfrentamento dos problemas vivenciados pelos trabalhadores no contexto do órgão, possibilitando, de um lado, melhorar a QVT e, de outro, melhorar a qualidade da prestação jurisdicional aos cidadãos-usuários, conciliando bem-estar e eficiência

No que se refere às limitações da pesquisa, o presente estudo contemplou apenas o diagnóstico macroergonômico. Quanto às perspectivas para agenda de pesquisa, sugere-se a realização do nível microergonômico, que possibilitaria a construção de um quadro mais completo do aspectos que impactam na QVT. É recomendável, também, replicar a pesquisa em médio prazo e de forma sistemática, visando à realização de estudo longitudinal.

A perspectiva é que a implantação de melhorias no contexto de trabalho pesquisado favoreça a prestação jurisdicional com celeridade e efetividade, e possibilite o efetivo exercício da cidadania pelos jurisdicionados por meio da realização da Justiça. Assim, todos - trabalhadores, órgão, Poder Judiciário e cidadãos - só tem a ganhar com um contexto de trabalho em que a QVT está presente. 


\section{Quality of working life and risk of disease: a study in the Brazilian judicial branch}

Abstract: The research attempted to characterize the Quality of Working Life (QWL) in an institution of the judicial branch based on the perception of its employees. The chosen methodological approach was the Activity-Centered Ergonomics Applied to the Quality of Working Life (ACEA_QWL). The participants were 5,164 workers. The quantitative analysis indicated that, overall, the institution is in a zone of moderate welfare. The most critical factor was work organization, while the factor evaluated most positively was the link between work and social life. The research provided subsidies for conducting an intervention that consolidates the welfare sources at work, aiming to the prevent health problems and promote QWL.

Keywords: quality of working life, welfare, malaise, activity-centered ergonomics, judicial branch.

\section{Qualité de vie au travail et des risques de maladie: étude dans le système judiciaire brésilien}

Résumé: Cette recherche visait à faire une caractérisation de la Qualité de Vie au Travail (QVT) dans une organization du pouvoir judiciaire brésilien, du point de vue des travailleurs. L'approche théorique et methodologique adoptée fut l'Ergonomie de I'Ativicté Apliquée au Qualité de Vie au Travail (EAA_QVT). Ont participé à la recherche 5.164 travailleurs. L'analyse quantitative a montrée, globalement, que les travailleurs evaluent la Qualité de Vie au Travail dans une échelle de bien-être moderée. Le facteur le plus critique fut "I'organisation du travail", alors que le facteur evalué le plus positif fut le "lien travail-vie sociale". La recherche a fourni des contribuitions visant les améliorations concernantes le bien-être, la prevention des maladies et la promotion de la QVT.

Mots-clés: Qualité de Vie au Travail, bien-être, ergonomie de l'activité, pouvoir judiciaire.

\section{Calidad de la vida laboral y el riesgo de enfermarse: estudio en el poder judicial brasileño}

Resumen: La investigación tuvo como objetivo caracterizar la Calidad de Vida Laboral (CVL) en una organización del Poder Judicial brasileño a través de la percepción de sus trabajadores. El enfoque teórico-metodológico adoptado fue la Ergonomía de la Actividad Aplicada a la Calidad de Vida en el Trabajo (EAA_CVT). Participaron de la pesquisa 5.164 trabajadores. El análisis cuantitativo mostró que, en escala global, los trabajadores evalúan la CVL en una zona de bienestar moderado. El factor más crítico fue la "organización del trabajo", mientras que el factor evaluado más positivamente fue el factor "relación trabajo-vida social". La pesquisa permitió proveer subsidios para una intervención que intenta consolidar las fuentes de bienestar, teniendo como objetivo la prevención de problemas de salud y la promoción de la CVL.

Palabras clave: Calidad de vida laboral; bienestar; malestar; ergonomía de la actividad; poder judicial.

\section{Referências}

Andrade, P. P. (2011). Sentimento de (In) justiça na Justiça: fatores (des) estruturantes de QVT sob a ótica dos servidores de um órgão do Poder Judiciário (Dissertação de Mestrado). Universidade de Brasília, Brasília, DF.

Barbosa, R. (1920). Oração aos moços. Recuperado de http://www.academia.org.br/abl/cgi/cgilua.exe/sys/start. htm?infoid=191\&sid=146

Bawden, D., \& Robinson, L. (2008). The dark side of information: Overload, anxiety and other paradoxes and pathologies. Journal of Information Science, 35(2), 180191.

Bellusci, S. M., \& Fischer, F. (1999). Envelhecimento funcional e condições de trabalho em servidores forenses. Revista de Saúde Pública, 33(6), 602-609.

Blanch, J. M., \& Stecher, A. (2009). La empresarización de servicios públicos y sus efectos colaterales. In T. Wittke \& P. Melogno (Orgs.), Psicología y organización del trabajo. Producción de subjetividad en la organización del trabajo (pp. 191-209). Montevideo: Psicolibros.

Bragard, I., Dupuis, G., Razavi, D., Reynaert, C., \& Etienne, A. M. (2012). Quality of work life in doctors working with cancer patients. Occupational Medicine, 62, 34-40.

Branquinho, N. G. S. (2010). Qualidade de vida no trabalho e vivênciasdebem-estaremal-estarno trabalho emprofessores da rede pública de ensino de Unaí/MG (Dissertação de Mestrado). Universidade de Brasília, Brasília.

Brasil. (2003). Gestão pública para um Brasil de todos: um plano de gestão para o governo Lula. Brasília: MP, SEGES.

Brasil, H. G. (2009). Psicodinâmica do trabalho: As vivências de prazer e sofrimento nas relações de trabalho entre servidores do quadro e terceirizados em uma organização do judiciário federal (Monografia de Especialização). Universidade de Brasília, Brasília, DF. 
Bruch, V. L. A., \& Monteiro, J. K. (2011). Relações entre colegas como manifestações de resistência ao adoecimento no trabalho. In J. N. G. de Araújo, C. P. de Almeida, M. C. Ferreira, \& A. M. Mendes (Orgs.), Dominação e resistência no contexto trabalho-saúde (pp. 121-140). São Paulo, SP: Mackenzie.

Caetano, V. C., Cruz, D. T., Silva, G. A., Leite, I. C. G., \& Carvalho, S. M. (2012). Processo saúde-doença: um estudo das representações sociais de trabalhadores com DORT. Physis, 22(3), 1047-1062.

Campos, T. L. (2008). O efeito da pressão de tempo na realização de tarefas de tradução: considerações sobre o produto tradutório. Revista da ABRALIN, 7(2), 223-241.

Carvalho, G. M. C., \& Moraes, R. D. (2011). Sobrecarga de trabalho e adoecimento no Polo Industrial de Manaus. Psicologia em Revista, 17(3), 465-482.

Conselho Nacional de Justiça. (2010). Morosidade processual da Justiça brasileira lidera reclamações na Ouvidoria. Recuperado de http://www.cnj.jus.br/noticias/69026morosidade-processual-da-justica-brasileira-liderareclamacoes-na-ouvidoria

Conselho Nacional de Justiça (2012). Documentos e Relatórios. Recuperado de http://www.cnj.jus.br/ ouvidoria-page/documentos

Daniel, J. B. (2012). É-feito de coisas burocráticas: impactos da organização do trabalho na qualidade de vida no trabalho em um órgão público federal (Dissertação de Mestrado). Universidade de Brasília, Brasília, DF.

Empresa Brasil de Comunicação (2013). Morosidade da Justiça é problema para reforma agrária, diz ministro do Desenvolvimento. Recuperado de http://www.ebc. com.br/noticias/agencia-brasil/2013/04/morosidade-dajustica-e-problema-para-reforma-agraria-diz-ministro

Feitosa, L. R. C. (2010). E se a orquestra desafinar? Contexto de produção e qualidade de vida no trabalho dos músicos da Orquestra Sinfônica de Teresina/PI. (Dissertação de Mestrado). Universidade de Brasília, Brasília, DF.

Fernandes, S. R. P., \& Vasques-Menezes, I. (2012). Organização do trabalho: implicações para a saúde do trabalhador. In M. C. Ferreira, \& H. Mendonça (Orgs.). Saúde e bem-estar no trabalho: dimensões individuais e culturais (pp. 261-275). São Paulo, SP: Casa do Psicólogo.

Ferreira, M. C. (2006). Qualidade de vida no trabalho. In A. D. Cattani \& L. Holzmann (Orgs.), Dicionário de trabalho e tecnologia (pp. 219-222). Porto Alegre, RS: UFRGS.

Ferreira, M. C. (2008). A ergonomia da atividade se interessa pela qualidade de vida no trabalho? Reflexões empíricas e teóricas. Cadernos de Psicologia Social do Trabalho, 11, 83-99.

Ferreira, M. C. (2009). Inventário de Avaliação de Qualidade de Vida no Trabalho (IA_QVT): Instrumento de Diagnóstico e Monitoramento de QVT nas Organizações. Anais da $61^{a}$ Reunião da Sociedade Brasileira para o Progresso da Ciência, Manaus, AM.

Ferreira, M. C. (2011). A ergonomia da atividade pode promover a qualidade de vida no trabalho? Reflexões de natureza metodológica. Revista Psicologia: Organizações e Trabalho, 11, 8-20.

Ferreira, M. C. (2012). Qualidade de vida no trabalho: uma abordagem centrada no olhar dos trabalhadores (2a ed.). Brasília, DF: Paralelo 15.

Franco, T., Druck, G., \& Seligmann-Silva, E. (2010). As novas relações de trabalho, o desgaste mental do trabalhador e os transtornos mentais no trabalho precarizado. Revista Brasileira de Saúde Ocupacional, 35(122), 229-248.

Gama, P., \& Roncaglia, D. (2013, 09 de maio). Faltaria guilhotina se o povo soubesse o que se passa, diz Alckmin. Folha de S. Paulo. Recuperado de http://www1.folha. uol.com.br/poder/2013/05/1275598-faltaria-guilhotinase-o-povo-soubesse-o-que-se-passa-diz-alckmin.shtml

Gomes, D. C., Silva, L. B., \& Sória, S. (2012). Condições e relações de trabalho no serviço público: o caso do governo Lula. Revista de Sociologia e Política, 20(42), 167-181.

Guérin, F., Laville, A., Daniellou, F., Duraffourg, J., \& Kerguelen, A. (2001). Compreender o trabalho para transformá-lo: A prática da ergonomia. São Paulo, SP: Blucher.

Jorge, S. M. (2009). A qualidade de vida no trabalho: Um estudo junto aos servidores públicos da Subseção Judiciária Federal de Campinas/SP (Dissertação de Mestrado). Universidade Metodista de Piracicaba, Piracicaba, SP, Brasil.

Lima, J. J., Santos Jr, G. \& Xavier, A. A. P. (2011). Análise de dependência da QVT sobre produtividade: estudo em operadores de caixa de uma praça de pedágio. Anais do I Congresso Brasileiro de Engenharia de Produção (CONBREPRO), Ponta Grossa, PR.

Moraes, A. (2006). Constituição do Brasil interpretada e legislação constitucional. (6a ed.). São Paulo, SP: Atlas.

Morosidade da Justiça fortalece a impunidade e estimula a corrupção, diz historiador. (2012, 19 de maio). Globo News. Recuperado de http://g1.globo.com/globo-news/ noticia/2012/03/morosidade-da-justica-fortaleceimpunidade-e-estimula-corrupcao-diz-historiador.html

Moura, J. T. (2009). Mudanças estruturais e administrativas e vivências de prazer e sofrimento no trabalho no âmbito da coordenadoria de taquigrafia de uma organização do Poder Judiciáriofederal. (Monografia de Especialização). Universidade de Brasília, Brasília, DF.

Norlund, S., Reuterwall, C., Höög, J., Lindahl, B., Janlert, U., $\&$ Birgander, L. S. (2010). Burnout, work conditions and gender - results from the Northern Sweden MONICA study. BMC Public Health, 10(326), 1-9.

Pacheco, V. A. (2011). Qualidade de vida no trabalho, bemestar e mal-estar sob a ótica de trabalhadores de uma agência reguladora no Brasil (Dissertação de Mestrado). Universidade de Brasília, Brasília, DF.

Padilha, V. (2010). Qualidade de vida no trabalho num contexto de precarização: A panaceia delirante. Trabalho, Educação e Saúde, 7(3), 549-563.

Prudêncio, C., Faria, J. E., \& Andrade, L. R. (2003). Modernização do Poder Judiciário: a justiça do futuro. Tubarão, SC: Studium. 
Putkonen, A. (2009). Predicting the effects of time pressure on design work. International Journal of Innovation and Learning, 6, 477-492.

Rice, E. M., Rady, M. Y., Hamrick, A., Verheijde, J. L., \& Pendergast, D. K. (2008). Determinants of moral distress in medical and surgical nurses and adult acute tertiary care hospital. Journal of Nursing Management, 16(3), 360-373.

Sadek, M. T. (2004). Judiciário: mudanças e reformas. Estudos Avançados, 18(51), 79-101.

Sadek, M. T., \& Arantes, R. B. (1994). A crise do Judiciário e a visão dos juízes. Revista USP, 21, 34-45.

Silva, I. B. (2004). A motivação dos juízes e servidores como técnica de eficiência. Revista CEJ, 24, 43-48.

Souza, N. (2013, 17 de março). Queremos justiça, ainda que tardia, diz viúva de Paulo Bandeira. G1 Alagoas. Recuperado de http://g1.globo.com/al/alagoas/ noticia/2013/03/queremos-justica-ainda-que-tardia-dizviuva-de-paulo-bandeira.html

Tavares, D. S. (2003). O sofrimento no trabalho entre servidores públicos: Uma análise psicossocial do contexto de trabalho em um tribunal judiciário federal (Dissertação de Mestrado) Universidade de São Paulo, São Paulo, SP.

Waters, T. R., Dick, R. B., \& Krieg, E. F. (2011). Trends in work-related musculoskeletal disorders: A comparison of risk factors for symptoms using quality of work life data from the 2002 and 2006 General Social Survey. Journal of Occupational and Environmental Medicine, 53(9), 1013-1024.

Yoshimine, R. (2012, 08 de novembro). Especialistas discutem estratégias para diminuir lentidão da Justiça. Jornal da Globo. Recuperado de http:/g1.globo.com/ jornal-da-globo/noticia/2012/11/especialistas-discutemestrategias-para-diminuir-lentidao-da-justica.html

Recebido: 21/08/2013

Revisado: 17/04/2014

Aceito: 03/10/2014 